This item was submitted to Loughborough's Research Repository by the author.

Items in Figshare are protected by copyright, with all rights reserved, unless otherwise indicated.

\title{
Scenario analysis as a tool for informing the design of behaviour change interventions
}

PLEASE CITE THE PUBLISHED VERSION

http://dx.doi.org/10.1007/978-3-319-20886-2_50

PUBLISHER

(c) Springer

VERSION

AM (Accepted Manuscript)

\section{PUBLISHER STATEMENT}

This work is made available according to the conditions of the Creative Commons Attribution-NonCommercialNoDerivatives 4.0 International (CC BY-NC-ND 4.0) licence. Full details of this licence are available at: https://creativecommons.org/licenses/by-nc-nd/4.0/

\section{LICENCE}

CC BY-NC-ND 4.0

\section{REPOSITORY RECORD}

Oliveira, Luis C.R., Martin Maguire, Val Mitchell, and Andrew May. 2019. "Scenario Analysis as a Tool for Informing the Design of Behaviour Change Interventions”. figshare. https://hdl.handle.net/2134/19014. 


\title{
Scenario analysis as a tool for informing the design of behaviour change interventions
}

\author{
Luis Oliveira, Martin Maguire, Val Mitchell, Andrew May \\ Loughborough Design School, Loughborough University, Leicestershire, LE11 3TU, UK \\ \{L.Oliveira, M.C.Maguire,V.A.Mitchell,A.J.May\}@lboro.ac.uk
}

\begin{abstract}
This article presents the design process behind the specification of a behaviour change intervention method to promote energy saving. The amount of energy used for food preparation is highly influenced by people's behaviours. A usercentred design approach based on scenario analysis was applied to provide understanding of context of use and specification of user requirements. This knowledge was applied to the design of behaviour change interventions to motivate sustainable behaviours.
\end{abstract}

Keywords: Scenarios, User-centred design, Behaviour change, Temporal tensions, Sustainability, Energy saving

\section{Introduction}

Societies have been increasingly concerned about the amount of carbon released into the atmosphere and the consequences of energy use. The housing sector accounts for more than one third of the energy consumption [1]. It is possible to build domestic products that use less energy via better product engineering, and to reduce the energy consumption by the way people use these products and perform their daily activities [2]. The energy efficiency of appliances has been increasing in recent years [3]. However, owning efficient appliances or living in energy efficient homes is not a guarantee that the energy use will reduce $[4,5]$. Furthermore, consumers are buying more appliances and having more standby devices [6].

The role of behaviour in domestic energy use is often the subject of research focusing on different appliances. Verhallen and Raaij [7] presented a study of the energy used for home heating, showing that occupant behaviours explain $26 \%$ of the variance of energy use. They demonstrated that levels of awareness, commitment to energy saving measures and personal preferences varied enormously from one person to another [7]. One study on washing up methods showed that people behave in diverse ways, and on average use more detergent, water, energy and time than a regular dishwasher [8]. But when a set of 'best practice tips' were given to consumers as instructions, they "used around $60 \%$ less water, 70\% less energy and 30\% less detergent compared with the average everyday behaviour the other subjects used. Additionally, they achieved a slightly better cleaning result” [9]. Cultural differences were shown to be an important factor on user behaviours for dish washing, influencing water and detergent usage [10]. Laundry and dish washing energy use was reported to be highly influenced by lifestyles, and "results show a variation of a factor of five between a more sustainable and a more careless behaviour” [11]. 
For cold appliances, video evidence shows that families have particular ways of storing and retrieving food from the fridge, and the frequency and length of interactions with the appliance can affect the energy consumption [12]. One user observation study demonstrated that people who perform their daily activities with a high level of interaction with kitchen appliances, sometimes cause unnecessary energy usage [13].

The amount of energy used for food preparation is highly influenced by people's behaviours. Cooking demands several interactions between users and appliances, the user is in close proximity during operation, and there are numerous energy saving behaviours that can be performed during the cooking activity [14]. There are also diverse techniques that the user can apply in order to reduce the energy use, depending on the food prepared $[15,16,17]$.

User-centred design methods can contribute to an understanding of how and why people use energy $[18,19]$, and this knowledge can inform the design of interventions to promote energy conservation. The design of behaviour interventions has been studied for many years across different disciplines [20]. The design of products and services can be used to motivate users to behave in a more sustainable way [21, 22, 23]. It is possible for designers to indicate a route they want users to take, via different methods and strategies. "Where users often make poor decisions, design can help counter this" [24]. Information and communication technologies (ICTs) can be used to increase the sustainability of products and services in many ways. Several examples can be found in the literature, from visualizations of resource consumption, and energy use feedback to persuasive applications [25, 26].

\subsection{Evidence from previous study}

As a previous study reported [27], people cook in diverse ways, using rather different procedures, resulting in diverse energy expenditure and time usage, even when cooking the same dish, using the same utensils and appliances. Participants rushed into the cooking tasks without much deliberation, consequently not following recommended preparation procedures and thus using more energy. Time issues and concerns about how long it takes to cook were recurrent aspects noted. Students generally boiled the kettle, preheated the hob, and used the bigger hob and high heat settings. Even though they wanted to cook quickly during the experiment, and to avoid extended preparation time, most of them used more water than needed, did not cover the pan, used more energy and eventually made the cooking process longer [27].

The interaction between participants and appliances during the cooking process presented a few moments of tension regarding the use of available time in relation to the task requirements [27]. The cooking activity could be divided in two main distinct phases. The first phase consists of the user preparing the utensils and ingredients to start cooking, and the second phase refers to when the user is cooking and waiting for the food to be ready. Participants' behaviours during these two phases and its relation to time indicate that both are distinct. The first phase includes activities like unpacking the food, selecting the pan and hob, pouring the water and setting everything ready to start the cooking process properly. The second phase constitutes, basically, stirring the food and watching it cook.

It was noted that there were temporal tensions during both phases of the cooking process. Temporal tensions are defined as the psychological construct arising from as- 
sessing the availability of temporal, mental, physical and social resources [28, 29]. The first phase is characterized by a hurrying feeling, when the time seemed to be short for the amount of preparation to be done. Some students performed different tasks at once, like pre-heating the hob whilst boiling the kettle, in an attempt to 'squeeze in' more actions "to fit in a time frame" [28]. The second phase denoted a waiting tension, when participants wanted to avoid the boredom of waiting by trying to make the cooking process quicker. The relationship between time and action is stretched, with participants anticipating outcomes that are about to happen [28] and trying to find distractions such as chatting or listening to music on their mobile phones. These two phases indicate a problematic situation where the availability of time in terms of the overall cooking goal could be better managed in order to avoid temporal tensions. Technology can be used to 'stretch time and slow things down' instead of only trying to make users to perform their activities more quickly [30].

Fig. 1, below, displays the timeline for cooking noodles with the different steps undertaken during the cooking process. It was inspired by service design thinking [31], following practical guidance from the Service Design Blueprint technique [32] and contributed to the definitions of the proposed behaviour change intervention.

The preparation phase consists of a number of steps to start the cooking process according to the proposed 'ideal' method. A careful selection of steps should be made in order to achieve the best final results in terms of the quality of food, effort, time and energy use. This would address the problem of students rushing into the cooking process without much consideration (phase 1) and often being tempted to do something to alleviate the waiting boredom (phase 2).

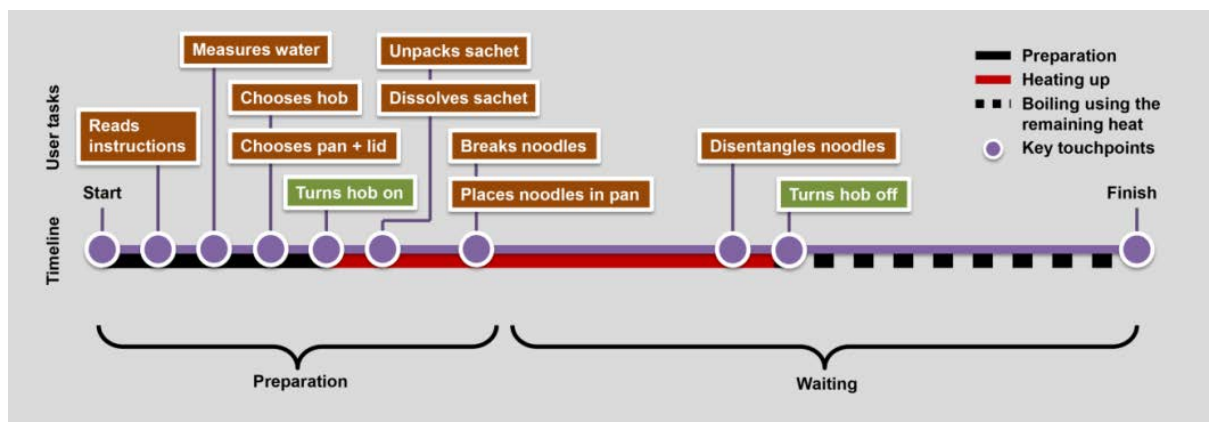

Fig. 1. Cooking timeline - Preparation and Waiting

The diagram above displays the preparation and waiting phases where a temporal tension might occur. Most participants failed to follow a procedure that could result in quicker preparation time and less energy use. They also seldom turned the hob off before the end of the cooking process in order to use the remaining heat stored in the metal plate. They wanted to avoid increasing the cooking time, indicating a temporal tension at the end of the process. 


\section{Scenario analysis}

In order to reduce temporal tensions during cooking, it is advised to incorporate the user's perspective into the development process. A user-centred design approach includes the understanding of context of use and specification of user requirements [33]. Following this approach, users were invited to generate new ideas that could contribute to the suitability and acceptance of such an intervention as described:

\section{$2.1 \quad$ The study}

A sample of the target population was selected to participate in an idea generation session. A group of 35 students participated on this study (12 females and 23 males). They were all undergraduate students registered for a module on research methods. Participation was voluntary and not related to their attendance records or grades. They could work alone or in pairs and it was not mandatory to complete all questions.

Participants were made aware of the aims and objectives of this research during the briefing phase and with the findings of the previous study [27] via images and graphs from previous chapters of the first author's thesis [14]. They were also presented with the cooking timeline diagrams to understand the temporal tensions observed during cooking. Finally they were prompted to think about the concept of a cooking assistant, a mobile phone application that could help during the cooking activity giving instructions for the preparation process.

\subsection{Methods}

To motivate a wider range of ideas, scenarios were also introduced into the exercise. 'Scenarios of use' is a widely recommended method for user-centred design [34], and can be useful during early stages of developments "to provide examples of future use as an aid to understanding and clarifying user requirements" [33]. Scenarios are "stories about people and their activities" [35], acting as "narrative descriptions of interactions between users and proposed systems" [36], that are typical and inserted into specific situations of use. The intention was to motivate students to consider the complexity of the cooking activity, elaborating on their own point of view but also simulating other experiences. When building different scenarios, it is important to ensure that they cover different 'stories', as they "must have some 'point' that illustrates a design issue not raised previously by other scenarios” [36]. A scenario can be built considering 4 aspects of each situation [35]:

1. Setting: the state and the background of the episode

2. Agents or actors: people involved in the episode

3. Goals or objectives: the changes that the agents wish to achieve

4. Actions or events: the plot, things that agents do and things that happen to them

Three different situations of cooking were presented to the students, who they asked to evaluate the introduction of an electronic cooking assistant into these scenarios. Then they were asked to contribute with ideas for aspects of the application that would motivate them to use it, follow the instructions and ultimately save energy for cooking. The proposed scenarios were: 
A. Cooking something quickly: when the student is cooking his food as usual, when she just wants to have food, to 'fuel up' when rushing between lectures, and having the kitchen as a routine space just to get things done.

B. Cooking as a private moment: when the student is more relaxed and experimenting with food, trying to be more creative and possibly cooking something new, not particularly concerned about the time taken for cooking

C. Cooking as a social experience: when the student is cooking together with friends or flatmates, sharing the experience and the food, using the kitchen as a social space to enjoy the company, chat and eat.

Table 1. Scenarios

\begin{tabular}{|llll|}
\hline Scenario & $\begin{array}{c}\text { A } \\
\text { Cooking something } \\
\text { quickly }\end{array}$ & $\begin{array}{c}\text { B } \\
\text { Cooking as a private } \\
\text { moment }\end{array}$ & $\begin{array}{c}\text { Cooking as a social } \\
\text { experience }\end{array}$ \\
\hline Setting & Kitchen as routine & $\begin{array}{l}\text { Kitchen as creative } \\
\text { space }\end{array}$ & $\begin{array}{l}\text { Kitchen as a social } \\
\text { space }\end{array}$ \\
\hline Agents & Student & Student & Friends \\
\hline Goals & Have food & $\begin{array}{l}\text { Relax, enjoy and } \\
\text { create }\end{array}$ & $\begin{array}{l}\text { Interact, enjoy, share } \\
\text { the experience }\end{array}$ \\
\hline Actions & Cook food as usual & $\begin{array}{l}\text { Experiment with } \\
\text { food, take time }\end{array}$ & $\begin{array}{l}\text { Chat, listen to music, } \\
\text { cook, taste }\end{array}$ \\
\hline
\end{tabular}

\subsection{Procedure}

After a briefing of the aims of the exercise, students were asked to discuss among themselves to elaborate creative solutions to the problems presented. One sheet of paper was handed to each student in order for them to complete a table with eight questions for each of the three scenarios. The questions were divided into two groups, corresponding to the two phases of distinct temporal tensions observed during the cooking process. The first phase, related to the 'preparation' phase, aimed to investigate the acceptance of the proposed mobile phone cooking assistant, and also to understand how to motivate students to take time to prepare the food with the correct process before rushing into the cooking itself. The second phase, namely "waiting”, was designed to understand how to make people wait without feeling bored during the process, and also what could a system suggest the user could do in order to avoid this boredom. The questions used were:

1. In this scenario, do you think students will follow instructions from an app?

2. Why? (reason for answer)

3. What would encourage students to follow a preparation procedure?

4. How to motivate them to think before acting?

5. In this scenario, do you think students will wait and follow the instructions?

6. Why? (reason for answer)

7. What would encourage them to take their time, not rush and not feel bored waiting?

8. What could an app suggest them to do? 


\subsection{Data analysis}

The dataset from this study comprised of 30 sheets with responses to these 8 questions shown above, for each of the three scenarios. A broad range of responses came from each one of these questions, and to organize them in themes, the software NVivo was used. This facilitated the categorization of responses and allowed a further qualitative data analysis. The software also enabled the researcher to build patterns from responses and provided a clearer picture of the data, following recommendations from [37].

Preliminary analysis of the responses and familiarization with the data indicated that dozens themes were raised by the participants. Further examination of the data indicated that responses could be merged into a smaller number of categories. Participants mentioned frequently the need to obtain a 'value' from the experience, that it should be useful to them in some way. They also wanted to enhance the process, gain confidence, experiment with food, increase the quality, improve health and have more enjoyment during the task. Another category of responses indicated that participants wanted to use less effort and have fewer distractions when cooking, and that a cooking assistant should be easy to use.

It was observed that these themes were falling into categories that matched the ones from existing models for evaluation of technology acceptance and suitability. Since this study involved the evaluation of the acceptance of an electronic assistant, the Technology Acceptance Model (TAM) [38] and its developments [39, 40, 41] provided a suitable framework to help in grouping and analysing participants' responses. TAM postulates that perceived usefulness and perceived ease of use are the fundamental determinants of user acceptance. Other factors were added later as influences on these main constructs, such as social influences external conditions [41].

Responses to all the open ended questions were classified into these 4 categories: Perceived usefulness, Perceived ease of use, Social influence and External factors.

Table 2. Scenarios results - overview

\begin{tabular}{|l|r|r|r|r|r|}
\hline TAM x scenarios & \multicolumn{1}{|c}{$\begin{array}{c}\text { A } \\
\text { Cooking } \\
\text { something } \\
\text { quickly }\end{array}$} & $\begin{array}{c}\text { Cooking as } \\
\text { a private } \\
\text { moment }\end{array}$ & $\begin{array}{c}\text { Cooking } \\
\text { as a social } \\
\text { experi- } \\
\text { ence }\end{array}$ & \multicolumn{2}{c|}{ Total } \\
\hline Perceived usefulness & 107 & 102 & 61 & 270 & 63.38 \\
\hline Perceived ease of use & 38 & 12 & 23 & 73 & 17.14 \\
\hline Social influence processes & 1 & 2 & 32 & 35 & 8.22 \\
\hline External variables & 21 & 16 & 11 & 48 & 11.27 \\
\hline Total & 167 & 132 & 127 & 426 & 100.00 \\
\hline
\end{tabular}

The majority of the responses from this study, aggregating all 6 open ended questions, fell into the category of perceived usefulness of the technology (63\%). Previous studies also identified that perceived usefulness is indeed the best predictor of technology acceptance, since it correlates more strongly to usage than ease of use [38], [41]. Perceived ease of use was the second most frequent item (17\%), followed by external variables (11\%) and social influence processes (8\%). 


\section{$3 \quad$ Results}

The semantic analysis of themes gathered during this study allowed the definition of the most important requirements in each scenario, for the two main phases of the cooking process. This data indicated that any proposed intervention should be useful by adding value to the cooking process. This value is perceived as any improvement in an aspect of cooking, such as increasing the speed of the cooking process, reducing mental workload or improving the user experience for cooking. These requirements are shown in Table 3 below.

Table 3. Scenarios and requirements

\begin{tabular}{|c|c|c|c|}
\hline Scenario & A & B & C \\
\hline $\begin{array}{l}\text { First phase - } \\
\text { preparation: } \\
\text { How to make } \\
\text { students use the } \\
\text { app and follow } \\
\text { instructions }\end{array}$ & $\begin{array}{l}\text { Make it useful } \\
\text { - Improve efficiency } \\
\text { - Make the cooking } \\
\text { process quicker, } \\
\text { easier, and save en- } \\
\text { ergy } \\
\text { - Improve quality, } \\
\text { make healthier } \\
\text { - Inform - benefits, } \\
\text { how to be quicker, } \\
\text { what can go wrong } \\
\text { Make it easy } \\
\text { - Easy to use } \\
\text { - Quick to use }\end{array}$ & $\begin{array}{l}\text { Make it useful } \\
\text { - Instigate gourmet / } \\
\text { experiment / creativi- } \\
\text { ty / skills } \\
\text { - Guarantee quality } \\
\text { - } \text { Save money } \\
\text { - Inform - instructions } \\
\text { on complex steps, } \\
\text { show benefits, what } \\
\text { can go wrong, feed- } \\
\text { back } \\
\text { Make it easy } \\
\text { - Improve visuals }\end{array}$ & $\begin{array}{l}\text { Make it useful } \\
\text { - Improve quality and } \\
\text { health } \\
\text { - Inform about benefits } \\
\text { and instructions on } \\
\text { complex steps } \\
\text { Make it easy } \\
\text { - Easy to use } \\
\text { - } \quad \text { Allow manage food } \\
\text { whilst with friends } \\
\text { Improve social aspects } \\
\text { - Promote social inter- } \\
\text { actions, engage } \\
\text { friends to contribute } \\
\text { - Impress friends with } \\
\text { food }\end{array}$ \\
\hline $\begin{array}{l}\text { Second phase - } \\
\text { waiting: } \\
\text { User require- } \\
\text { ments - how to } \\
\text { make students } \\
\text { wait }\end{array}$ & $\begin{array}{l}\text { Make it useful } \\
\text { - Concentrate on } \\
\text { food - Suggest how } \\
\text { to improve speed, } \\
\text { health and quality } \\
\text { - Give external dis- } \\
\text { tractions - read, } \\
\text { work, quiz, games, } \\
\text { tips on energy, } \\
\text { cooking, relax } \\
\text { - Multitasking - } \\
\text { prepare other parts } \\
\text { of the dish, wash } \\
\text { up, set table }\end{array}$ & $\begin{array}{l}\text { Make it useful } \\
\text { - Concentrate on food } \\
\text { - suggest ingredients, } \\
\text { how to improve } \\
\text { speed, health, quality } \\
\text { - Give external distrac- } \\
\text { tions - read, work, } \\
\text { other tasks, tips on } \\
\text { energy saving, waste } \\
\text { use and better cook- } \\
\text { ing } \\
\text { - Multitask - other part } \\
\text { of the dish, wash up, } \\
\text { clear up, set table }\end{array}$ & $\begin{array}{l}\text { Make it useful } \\
\text { - Concentrate on food - } \\
\text { How to improve } \\
\text { speed, health, quality } \\
\text { - } \text { Guide multitasking - } \\
\text { inform how to prepare } \\
\text { other dishes simulta- } \\
\text { neously } \\
\text { - Enhance social as- } \\
\text { pects - share tasks } \\
\text { with others, involve, } \\
\text { give conversation top- } \\
\text { ics, use online social } \\
\text { networks }\end{array}$ \\
\hline
\end{tabular}

Data gathered during this session indicated the primary need was to consider the perceived usefulness of the application, and as a secondary consideration the proposed app needed to be perceived as easy to use in order to be adopted. Concepts of a richer user experience (UX) [42] were also suggested, including fun elements (games, quizzes, relaxing activities, social interactions) and improved visual appearance. Some external 
variables such as social factors can also influence the acceptance of technology, but to a lesser extent. In summary, participants required that the technology must fit the task they attempt to perform [43]. In line with previous studies involving the Technology Acceptance Model [38], [44] students need to recognize the application as being able to help them to accomplish the goal during the activity, preferably with added fun, otherwise it might not be perceived as useful, consequently failing to be really accepted.

\subsection{The proposed intervention}

Data from the studies conducted during this phase combined with the literature review indicated that participants need to perceive a benefit from using the application. Often people want to see the rewards from specific behaviours, as if asking 'what is in there for me?' [45]. The strategies developed here focus on the results of the scenario analysis and previous studies by providing benefits to the user including a shorter cooking time, a convenient process, and the possibility to have the final meal prepared according to their preferences, in a facilitated way. In order to design the application to be useful, reduce temporal tensions and promote energy saving, the strategy of applying persuasive technology was considered [46, 47]. From their examples of persuasive technologies as tools, it is possible to select strategies that could be embedded within an intervention intended to influence people's behaviours whilst cooking.

\subsection{Structure of the application}

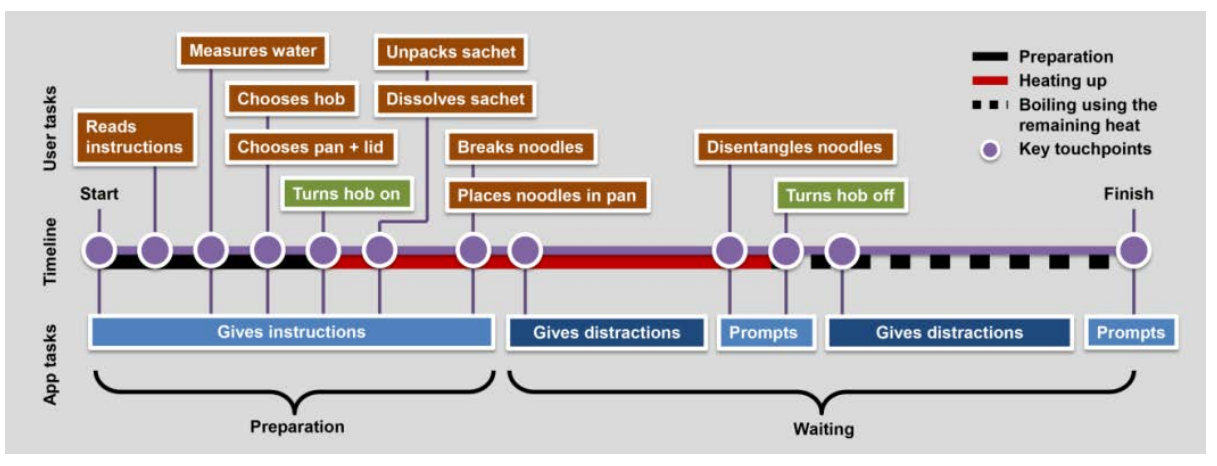

Fig. 2. Cooking timeline: user and app tasks

Continuing from Fig. 1, which presented the moments of temporal tension during cooking, Fig. 2, above, shows opportunities for a system to intervene during the cooking activity and to ultimately reduce these temporal tensions. Based on the Service Design Blueprint [32], this diagram includes the timeline, the physical evidences and inputs, the visible user actions, the 'checkpoints' and also the backstage actions that could be performed by the cooking application (bottom row of boxes). The roles of the user and a cooking agent are interrelated in order to produce an ideal process, aiming at energy saving, shorter cooking time, improved food quality, less effort and reduced temporal tensions. 


\section{Discussion}

Providing some sort of distraction during the waiting phase of cooking could be one of the strategies designed to reduce temporal tensions. Introducing one activity that provides cognitive absorption [48] during the second phase of the cooking process could work for this purpose, making time pass quickly during an engaging activity. It is argued that it is possible to develop interventions to foster flow, an ideal state when the challenges of the environment matches personal skills [49]. These interventions are generally used to make regular work settings a better source of flow giving more enjoyable interactions, with built-in goals, feedback, rules and challenges, without imposed demands or strict pacing. In a state of flow there is "a sense that one's skills are adequate to cope with the challenges at hand, in a goal-directed, rule-bound action system that provides clear clues as to how well one is performing. Concentration is so intense that there is no attention left over to think about anything irrelevant, or to worry about problems" [50]. Flow is much more likely to happen from a structured activity, and activities performed with flow can lead to a self-motivated dimension of behaviour [51]. Although flow theory is generally applied to playful activities, previous research found correlations between measurements of flow and use of office software such as spreadsheet and email tools [52] or internet browsing [53].

Oulasvirta and Tamminen [28] indicate the possibility of use of notifications as a form of reducing temporal tensions. Users could "delegate tasks to automatic devices that must somehow notify the user of important changes in the controlled task or process". The evidence that some students lost track of time during cooking, and the cognitive load associated with the task of calculating the duration of the cooking process (for even a simple cooking task) indicates that electronic timers with prompts can improve the time management for the activity. "By creating a system that does not demand a continual awareness of time progression, opportunities for engaging in activities that reduce the time pressure may be increased" [54]. ICT interfaces can provide a better support for allocation of attention, via context-triggered audible or tactile alerts intervening at the right time and leaving the users to dedicate their cognitive resources to the cooking activity itself. This aid could be provided through an electronic timer with prompts programmed for the specific meal being cooked to alert the user at the end of each step, allowing them to concentrate on the cooking actions. This suggests an appropriate allocation of function between user and system or in other words, "It is important to determine which aspects of a job or task should be handled by people and which can be handled by software and hardware" [33]. Previous research also recommends that systems should minimize the attention required by technology by decreasing the need for visual attention. The user should be able to concentrate on the environment and receive multimodal feedback at an appropriate time [55].

Other advantages of using a timer are that participants would not need to rely on their senses for assessing when the food is ready, such as looking or tasting, as observed during the trials, and reducing the inclination to allow the food cooking for longer than necessary. Timers and alerts could enable users to reduce the electricity usage by informing them when to switch the heat source off and use the remaining heat retained in the hob. 


\section{Conclusion}

This paper addresses the topic of time management during cooking activities, aligned with a theoretical background on time perceptions and temporal tensions. This knowledge indicated the media and the content of an intervention to tackle wasteful behaviours. These propositions were presented to a group of students who analysed it according to specific scenarios. Their contributions confirmed the findings from previous studies that an application can contribute to make the cooking process more efficient (reducing time to prepare, minimizing effort involved and providing better results) and improve the user experience. The app could help users concentrate on the food preparation in order to follow a recommended procedure for efficiency and energy saving. At the same time, an app could provide a variety of distractions during the second phase of the cooking to minimize boredom, such as tips for better cooking, multitasking, quizzes, games and relaxation activities.

The qualitative data analysis from the requirements study showed that individuals are likely to be cautious in adopting a cooking assistant app because they do not want to spend additional time preparing the food, complicate the process, or compromise the quality of food. However, if the application has a value, or is perceived as being useful and easy to use, then it is more likely to be accepted. This information contributed to the process of specifying the design of a persuasive electronic intervention, for example via a mobile phone application, to change their behaviours for cooking.

The main hypothesis formulated here is that providing a way to reduce temporal tensions during cooking can improve the user experience and promote energy saving. It was demonstrated that ICT can provide the tools needed to manipulate time perceptions and therefore bring about changes in the specific behaviours that result in unnecessary energy usage. The developed application should be evaluated to understand its effectiveness in changing behaviours and achieving acceptance among the target population.

\section{References}

1. Department for Energy and Climate Change.: UK Energy in Brief 2010, http://www.uea.ac.uk/ e680/energy/pdf_files/energy_in_brief/190-ukenergy-in-brief-2010.pdf

2. Attari, S.Z., Dekay, M.L., Davidson, C.I., Bruine De Bruin, W.: Public Perceptions of Energy Consumption and Savings. Proceedings of The National Academy of Sciences 107, 16054-16059 (2010)

3. Geller, H., Harrington, P., Rosenfeld, A.H., Tanishima, S., Unander, F.: Polices for Increasing Energy Efficiency: Thirty Years of Experience In OECD Countries. Energy Policy 34, 556-573 (2006)

4. Crosbie, T., Baker, K.: Energy-Efficiency Interventions in Housing: Learning From The Inhabitants. Build. Res. Inf. 38, 70-79 (2010)

5. Gill, Z., Tierney, M.J., Pegg, I.M., Allan, N.: Low-Energy Dwellings: The Contribution of Behaviours to Actual Performance. Build, Res, Inf., 38, 491-508 (2010)

6. Firth, S., Lomas, K., Wright, A., Wall, R.: Identifying Trends in the Use of Domestic Appliances from Household Electricity Consumption Measurements. Energy and Buildings 40, 926-936 (2008)

7. Verhallen, T.M.M., Raaij, W.F.V.: Household Behavior and the Use of Natural Gas for Home Heating. J. Consumer Res. 8, 253-257 (1981)

8. Berkholz, P., Stamminger, R., Wnuk, G., Owens, J., Bernarde, S.: Manual Dishwashing Habits: An Empirical Analysis of UK Consumers. Int. J. of Consumer Stud. 34, 235-242 (2010) 
9. Fuss, N., Bornkessel, S., Mattern, T., Stamminger, R.: Are Resource Savings in Manual DishWashing Possible? Consumers Applying Best Practice Tips. International Journal of Consumer Studies 35, 194-200 (2011)

10. Elizondo, G.M., Lofthouse, V., Bhamra, T.: An Exploration of Dishwashing Habits in Anglo and Hispanic Communities through the Use of Cultural Probes. In: International Consumer Sciences Research Conference (ICSRC), Bonn, Germany, July 18-20 (2011)

11. Stickdorn, M., Schneider, J.: This is Service Design Thinking. BIS Publishers, Amsterdam (2010)

12. Tang, T., Bhamra, T.: Putting Consumers First in Design for Sustainable Behaviour: A Case Study of Reducing Environmental Impacts of Cold Appliance Use. Int. J. Sustain. Eng. 5, 4, 288-303.

13. Elias, E.W.A., Dekoninck, E.A., Culley, S.J.: Assessing User Behaviour for Changes in the Design of Energy Using Domestic Products. In: IEEE International Symposium on Electronics and the Environment, May 19-22, 1-6 (2008)

14. Oliveira, L.: Designing and Evaluating a Behaviour Change Intervention that Introduces Modification of Time Perceptions as a Solution to Promote Sustainable Behaviours, PhD thesis, Loughborough Design School, Loughborough University, UK (2013)

15. Das, T., Subramanian, R., Chakkaravarthi, A., Singh, V., Ali, S.Z., Bordoloi, P.K.: Energy Conservation in Domestic Rice Cooking. J. Food Eng. 75, 156-166 (2006)

16. Oberascher, C., Stamminger, R., Pakula, C.: Energy efficiency in daily food preparation. International Journal of Consumer Studies 35, 201-211 (2011)

17. Webster, J., Trevino, L.K., Ryan, L.: The Dimensionality and Correlates of Flow in HumanComputer Interactions. Comput. Hum. Behav. 9, 411-426 (1993)

18. Kuniavsky, M.: Observing the User Experience: A Practitioner's Guide to User Research. Morgan Kaufmann, USA (2003)

19. Stamminger, R.: Modelling Resource Consumption for Laundry and Dish Treatment in Individual Households for Various Consumer Segments. Energy Efficiency 4, 559-569 (2011)

20. Fishbein, M., Ajzen, I.: Predicting and Changing Behavior. Taylor \& Francis, London (2010)

21. Beale, R.: Slanty Design. Commun. ACM 50, 1, 21-24 (2007)

22. Bhamra, T., Lilley, D., Tang, T. Design for Sustainable Behaviour: Using Products to Change Consumer Behaviour. Design Journal 14, 427-445 (2011)

23. Jelsma, J., Knot, M.: Designing Environmentally Efficient Services; A 'Script' Approach. J. Sustain. Product Design 2, 119-130 (2002)

24. Lockton, D., Harrison, D., Stanton, N.A.: The design with Intent Method: A Design Tool for Influencing User Behaviour. Applied Ergonomics 41, 3, 382-392 (2010)

25. Disalvo, C., Sengers, P., Brynjarsdóttir, H.: Mapping the Landscape of Sustainable HCI. In: Proceedings of the 28th International Conference on Human factors in Computing Systems, April 1015, ACM Press, 1975-1984 (2010)

26. Goodman, E.: Three Environmental Discourses in Human-Computer Interaction. In: Proceedings of the 27th International Conference Extended Abstracts on Human Factors in Computing Systems (CHI EA ’09). ACM Press, New York, NY, USA, 2535-2544 (2009)

27. Oliveira, L., Mitchell, V., Badni, K.: Cooking Behaviours: A User Observation Study to Understand Energy Use and Motivate Savings. Work: A Journal of Prevention, Assessment and Rehabilitation 41, Supplement 1, 2122-2128 (2012)

28. Oulasvirta, A., Tamminen, S.: Temporal Tensions in Human-Computer Interaction. In: CHI’04 Workshop on Temporal Aspects of Work (2004)

29. Oulasvirta, A., Tamminen, S., Roto, V., Kuorelahti, J.: Interaction in 4-Second Bursts: The Fragmented Nature of Attentional Resources in Mobile HCI. In: Proceedings of SIGCHI Conference on Human Factors in Computing Systems (CHI 2005), ACM Press, New York 919-928 (2005)

30. Hallnäs, L., Redström, J.: Slow Technology-Designing for Reflection. Pers. Ubiq. Comput. 5, 3, 201-212 (2001)

31. Tang, T., Bhamra, T.: Understanding Consumer Behaviour to Reduce Environmental Impacts through Sustainable Product Design. In: Undisciplined! Design Research Society Conf., 1-15 (2008) 
32. Bitner, M.J., Ostrom, A.L., Morgan, F.N.: Service Blueprinting: A Practical Technique for Service Innovation. California Manage. Rev. 50, 66 (2008)

33. Maguire, M.: Methods to Support Human-Centred Design. Int. J. Hum. Comput. Stud. 55, 1, 587634 (2001)

34. Bevan, N.: UsabilityNet Methods for User Centred Design. Human-Computer Interaction: Theory and Practice (Part 1), 1, 434-438 (2003)

35. Carroll, J.M.: Five Reasons for Scenario-Based Design. Interact. Comput. 13, 1, 43-60 (2000)

36. Potts, C. Using Schematic Scenarios to Understand User Needs. In: Proceedings of the 1st Conference on Designing Interactive Systems: Processes, Practices, Methods, \& Techniques, ACM Press, 247-256 (1995)

37. Braun, V., Clarke, V.: Using Thematic Analysis in Psychology. Qual. Res. in Psych. 3, 2, 77-101 (2006)

38. Davis, F.D.: Perceived Usefulness, Perceived Ease of Use, and User Acceptance of Information Technology. MIS Quarterly 13, 3, 319-340 (1989)

39. Venkatesh, V.: Determinants of Perceived Ease of Use: Integrating Control, Intrinsic Motivation, and Emotion into the Technology Acceptance Model. Inform. Syst. Res. 11, 4, 342-365 (2000)

40. Venkatesh, V., Davis, F.D.: A Theoretical Extension of the Technology Acceptance Model: Four Longitudinal Field Studies. Manage. Sci. 46, 2, 186-204 (2000)

41. Venkatesh, V., Bala, H.: Technology Acceptance Model 3 and a Research Agenda on Interventions. Decision Sci. 39, 273-315 (2008)

42. Anderson, S.P.: Seductive Interaction Design: Creating Playful, Fun, and Effective User Experiences. New Riders, Berkeley, CA (2011)

43. Goodhue, D.L., Thompson, R.L.: Task-Technology Fit and Individual Performance. MIS Quarterly 19, 2, 213-236 (1995)

44. Verhallen, T.M.M., Raaij, W.F.V.: Household Behavior and the Use of Natural Gas for Home Heating. J. Consumer Res. 8, 253-257 (1981)

45. Foster, D., Lawson, S., Wardman, J., Blythe, M., Linehan, C.: 'Watts in it for Me?': Design Implications for Implementing Effective Energy Interventions in Organisations. In: Proceedings of the 2012 ACM Annual Conference on Human Factors in Computing Systems, Austin, Texas, USA (CHI 2012), Anonymous ACM, New York, USA, 2357-2366 (2012)

46. Fogg, B.J.: Persuasive Computer: Using Technology to Change What We Think and Do. Morgan Kaufman, San Francisco, CA, USA (2003)

47. Oinas-Kukkonen, H., Harjumaa, M.: Persuasive Systems Design: Key Issues, Process Model, and System Features. Commun. Assoc. Inform. Syst. 24, 28, 485-500 (2009)

48. Agarwal, R., Karahanna, E.: Time Flies When You're Having Fun: Cognitive Absorption and Beliefs about Information Technology Usage. MIS Quarterly 24, 4, 665-694 (2000)

49. Nakamura, J., Csikszentmihalyi, M.: The concept of flow. In: Handbook of Positive Psychology, C.R. Snyder, E. Wright, S. Lopez, Eds., 89-105 (2002)

50. Csikszentmihalyi, M.: Flow: The Psychology of Happiness: The Classic Work on How to Achieve Happiness. Rider, London (2002)

51. Csikszentmihalyi, M.: Beyond Boredom and Anxiety. Jossey-Bass (Wiley), San Francisco (2000)

52. Wood, G., Newborough, M.: Influencing User Behaviour with Energy Information Display Systems for Intelligent Homes. Int. J. Energy Res. 31, 1, 56-78 (2007)

53. Novak, T.P., Hoffman, D.L., Yung, Y.F.: Measuring the Customer Experience in Online Environments: A Structural Modeling Approach. Marketing Science 19, 1, 22-42 (2000)

54. Martin, R., Holtzman, H.: Kairoscope: Managing Time Perception and Scheduling through Social Event Coordination. In: Proceedings of the 2011 annual conference on Human factors in computing systems, ACM Press, 1969-1978 (2011)

55. Rogers, Y., Sharp, H., Preece, J.: Interaction Design: Beyond Human Computer Interaction. John Wiley and Sons, Chichester, West Sussex, UK (2011) 